\title{
Effectiveness of low level laser used in the prevention and treatment of oral mucositis in patients with breast cancer undergoing adjuvant chemotherapy
}

\author{
Antonio Eugenio Magnabosco Neto, Fernando Henrique Westphalen \\ Cirurgia Bucomaxilofacial - Estomatologia, Brazil
}

\begin{abstract}
Correspondence: Antonio Eugenio Magnabosco Neto, Cirurgia Bucomaxilofacial - Estomatologia, Address: Rua Blumenau, I78, S 608, Medclínicas Building - Joinville / SC, Brazil,Tel (47) 3433-4347; (47) 999I6-0828, Email aemagnabosco@terra.com.br
\end{abstract}

Received: July 22, 2018 | Published: August 21, 2018

Copyright@ 2018 Neto et al. This is an open access article distributed under the terms of the Creative Commons Attribution License, which permits unrestricted use, distribution, and reproduction in any medium, provided the original author and source are credited.

\begin{abstract}
The tissues of the oral cavity are prone to toxicity from antineoplastic agents, and oral mucositis is the most common manifestation of stomatoxicity in medical oncology, a priority is given for prevention and/or control of this condition, our study presents a sample of 24 adult patients with breast cancer treated at the Municipal Hospital St. Joseph Joinville (Santa Catarina) between May and November 2011, patients underwent adjuvant chemotherapy using a combination of fluorouracil (5-FU)+adriamycin (doxorubicin)+cyclophosphamide (FAC). The examination of the mucosa to determine the degree of mucositis was done by a qualified professional only for the study. In total, were assessed twice on the fifth day of oral therapies segments of the three groups included in the study. The influence of laser irradiation was investigated, $660 \mathrm{~nm} \mathrm{InGaA1P}\left(40 \mathrm{~mW}, 4.0 \mathrm{~J} / \mathrm{cm}^{2}\right)$ and $808 \mathrm{~nm} \mathrm{AsGaAl}\left(120 \mathrm{~mW}, 4.0 \mathrm{~J} / \mathrm{cm}^{2}\right)$ in the experimental groups 1 and 2 , respectively, the control group received a solution of $0.12 \%$ chlorhexidine without alcohol, and injury severity in the laser group was lower than in the control group no statistical difference between the two wavelengths appointed, these results demonstrate that the low intensity laser radiation can be applied to reduce chemotherapy induced stomatitis and subsequently to promote improvement in the quality of life of patients receiving treatment for cancer.
\end{abstract}

Keywords: hypocellularity, osteonecrosis, bisphosphonates, radiotherapy, BRONJ

\section{Introduction}

The primary aim of cancer treatment is eradication of the disease. ${ }^{1}$ The increasing success of antineoplastic treatments can be attributed to the use of immunosuppressive therapies, such as chemotherapy, and to the combination of their agents with increasingly higher doses, however, the toxicity of these medications remains a serious clinical problem since it negatively impacts patients' psychosomatic balance and quality of life..$^{2-4}$

Oral mucositis $(\mathrm{OM})$ has significant repercussions on the quality of life of cancer patients, and its occurrence is related to the toxic effects of chemotherapy. ${ }^{5}$ These effects stem from the non-selective action of the antineoplastic agents against any cells with a high mitotic rate. This reduces the ability for cell renewal of epithelial tissue, hampering the regeneration of injured mucosa. ${ }^{6,7}$ In addition, when associated with xerostomia mucositis contributes to atrophy of the oral mucosa, predisposing it to ulceration which may lead to secondary infection and/or spontaneous hemorrhaging. ${ }^{8}$ The clinical consequences of mucositis are therefore directly linked to the severity of the chemotherapy regimen proposed in the initial cancer treatment plan. ${ }^{9}$ Some studies have been conducted in an effort to define the histologic changes in oral mucosa caused by chemotherapeutic agents. The most common histologic alterations include epithelial hyperplasia and collagen degeneration. ${ }^{10}$
All regions of the oral cavity can be affected. However, incidence is highest in non-keratinized surfaces such as the cheek and lip mucosa, floor of the mouth, ventral aspect of the tongue, and soft palate. Lesions are invariably accompanied by symptomatology ranging from mild burning to severe pain. ${ }^{11-13}$

OM typically manifests between the third and seventh day after commencement of antineoplastic treatment with signs and symptoms such as discomfort, burning sensation, and erythema, besides difficulties speaking and swallowing solid food and liquids.9 Ulcerative lesions limit mastication and expose the patient to infection by opportunist microorganisms..$^{14-16}$

Evidence has shown that low-level laser therapy (LLLT) can reduce the incidence and severity of chemotherapy-induced mucositis. ${ }^{2,6,9,17}$ LLLT is an atraumatic, simple and effective technique for the prevention and repair of these lesions. ${ }^{18,19}$ The approach is based on photophysical, photobiological and photochemical effects. When light of a specific density and energy interacts with biological tissue, a process of cellular repair is triggered, particularly among cells with debilitated function. ${ }^{20-25}$

The aim of this study was to assess the effectiveness of lowlevel AsGaAl laser, applied in association with oral hygiene care,
Submit your Article | www.ologyjournals.com/submit-article OP Ology $f$ in $y$ ress
Citation: Neto AEM, Westphalen FH. Effectiveness of low level laser used in the prevention and treatment of oral mucositis in patients with breast cancer undergoing adjuvant chemotherapy.J Dent Maxillofacial Res. (20 I8); I (2):79-83. DOI: $10.30881 /$ jdsomr.00016 
for reducing the severity of oral mucositis induced by use of the combination of antineoplastic agents: fluorouracil (5-FU), adriamycin (doxorubicin) and cyclophosphamide in breast cancer patients. Additionally, the effects of application of InGaA1P and AsGaAl laser at the two wavelengths of $660 \mathrm{~nm}$ and $808 \mathrm{~nm}$ were compared.

\section{Materials and methods}

\section{Laser used in the study}

Manufacturer: MM Optics LTDA, Mark: Twin Flex Evolution, São Carlos, SP, Brazil.

\section{Prophylactic application}

$0.12 \%$ alcohol-free chlorhexidine solution (REYMER DO BRASIL Ind e Com. LTDA, Aparecida de Goiânia, GO, Brazil).

\section{Scanning protocol}

Group 1: received treatment with low-level laser therapy at a wavelength of $660 \mathrm{~nm}+/-10 \mathrm{~nm}$, power of $40 \mathrm{~mW}$, and energy of $4.0 \mathrm{~J} /$ $\mathrm{cm}^{2}$. (Semiconductor active medium: InGaA1P red laser)

Group 2: received irradiation with low-level laser therapy at a wavelength of $808 \mathrm{~nm}+/-10 \mathrm{~nm}$, power of $120 \mathrm{~mW}$, and energy of $4.0 \mathrm{~J} /$ $\mathrm{cm}^{2}$. (Semiconductor active medium: $\mathrm{AsGaAl}$ infrared laser)

The red laser was used in single-point mode, $5 \mathrm{~s}$ per point, while infrared laser was used in sweep mode, 10s per segment. Applications were started 2 days prior to commencement of chemotherapy and given once a day at 24-h intervals.

Were covered ten areas of the oral cavity for prophylactic laser application:

i. Upper and lower labial mucosa, right and left buccal mucosa, hard palate, soft palate, upper and lower gums, floor of mouth, tongue (belly and back right and left/right edge and left).
Group 3: (control) received only a prophylactic application of $0.12 \%$ alcohol-free chlorhexidine solution twice per day every $12 \mathrm{~h}$ for a period of three days. Patients were instructed to perform a mouth rinse approximately thirty minutes after tooth brushing and to refrain from ingesting water for the proceeding 20 minutes.

OM severity was assessed clinically by the researchers according to the World Health Organization (WHO) scale and by the Visual Analogue Scale (VAS) for measuring pain. All patients received guidance on oral hygiene practice prior to the study.

A descriptive, prospective, randomized case study was carried out. This study was carried out with the clinical records of subjects regularly attending the Oncology Department of the São José Hospital, in the city of Joinville, Santa Catarina State, with the opinion of the committee of ethics in research under number 10034 and the opinion of the National Commission on Ethics in Research-CONEP-under the number $356939 \mathrm{FR}$. All subjects signed an informed consent to allow the researchers to use their data.

The sample consisted of 24 female breast cancer patients, between 34 and 60years old, without lymph node involvement and undergoing chemotherapy with the FAC combination at the following dosages: $500 \mathrm{mg} / \mathrm{m}^{2}$ of 5 -fluorouracil, $50 \mathrm{mg} / \mathrm{m}^{2}$ of doxorubicin and $500 \mathrm{mg} / \mathrm{m}^{2}$ of cyclophosphamide. Doses were calculated based on body surface area and infused endovenously for approximately $2 \mathrm{~h}$ programmed on five consecutive days for a total of 6 cycles interspersed with intervals of 28 days.

Patients were allocated sequentially into three groups, each containing eight patients, with one type of laser treatment per group, as shown in Table 1. Examination of the oral mucosa to determine the degree of mucositis was performed by a single professional responsible for the study. In total were assessed twice on the fifth day of oral therapies segments of the three groups included in the study.

Table I Type of therapy applied to each group and physical parameters used

\begin{tabular}{|c|c|c|c|c|c|c|}
\hline Groups & Period & Therapy applied & & & & \\
\hline $\operatorname{RLG}(n=8)$ & 2 days & $40 \mathrm{~mW}$ & $4.0 \mathrm{~J} / \mathrm{cm}^{2}$ & $5 s$ & $660 \mathrm{~nm}$ & Single Point \\
\hline $\operatorname{IRLG}(\mathrm{n}=8)$ & 2 days & $120 \mathrm{~mW}$ & $4.0 \mathrm{~J} / \mathrm{cm}^{2}$ & $10 \mathrm{~s}$ & $808 \mathrm{~nm}$ & Sweep \\
\hline$C G(n=8)$ & 2 days & Alcohol-free, $0.12 \%$ & hlorhexidi & & & \\
\hline
\end{tabular}

RLG, red laser group, IRLG, infrared laser group, CG, control group.

\section{Statistical analysis of data}

Patients were assessed on the fifth day of antineoplastic therapy for collection of results, giving a total of 6 assessments considering two evaluations per group. The data were submitted to descriptive statistical analysis using distribution of frequencies. Frequencies for each degree of OM severity observed in the three separate groups were compared using the Fisher-Freeman-Halton (FFH) test. Upon observation of a significant difference on the test, multiple comparisons for proportions were performed using permutation tests (resampling method) considering 20,000 replications. All significance probabilities were of the bilateral type and values under 0.05 were deemed statistically significant. The SAS 9.3 (Statistical Analysis System, Institute Inc., Cary, NC, USA) software package was used for statistical analyses of the data.

\section{Results}

The sample consisted of 24 female patients with a mean age of $47 y e a r s$ (range: 34 to 60years).

Table 2 shows the clinical distribution of the 24patients who received combination therapy with 5-fluorouracil, doxorubicin and cyclophosphamide and developed oral mucositis. Percentage distribution of degree of OM severity observed for the two treatment groups and the control group is also given. In the laser irradiated groups, 7 patients $(29.16 \%)$ had Grade 0 OM while a further 7 patients $(29.16 \%)$ had Grade 1 OM severity on the WHO scale. Taken together, cases Graded as 0 and 1 accounted for $58.32 \%$ of the overall sample. All Grade 3 cases occurred in the Control Group (5 patients, $20.84 \%$ of total). 
Table 2 Final assessment of oral mucositis severity in experimental and control groups on the WHO scale

\begin{tabular}{lllll}
\hline & \multicolumn{2}{l}{ Group } & & \\
\cline { 2 - 4 } Grading on WHO scale & $\mathbf{R L G ( n = 8 )}$ & IRLG(n=8) & CG(n=8) & n(\%) \\
\hline Grade 0 & 3 & 4 & - & $7(29.16 \%)$ \\
Grade I & 4 & 3 & - & $7(29.16 \%)$ \\
Grade 2 & $\mathrm{I}$ & $\mathrm{I}$ & 2 & $4(16.66 \%)$ \\
Grade 3 & - & - & 5 & $5(20.84 \%)$ \\
Grade 4 & - & - & $\mathrm{I}$ & $\mathrm{I}(4.16 \%)$ \\
Total & 8 & 8 & 8 & $24(100 \%)$ \\
\hline
\end{tabular}

RLG, red laser group, IRLG, infrared laser group, CG, control group.

Source: Oncology Sector, Hospital Municipal São José, Joinville(Santa Catarina state), Brazil.

Table 3 shows results of interpretative analysis of the difference in frequency of occurrence of the different grades of OM severity. No significant difference was observed in the frequencies of Grade 0 cases among the three groups $(p=0.1302$, Fisher-Freeman-Halton Test). An analogic interpretation was carried out for Grades 1,2 and 4. Based on Fisher's exact test.

However, a significant difference in frequency of occurrence of Grade 3 cases was observed among the 3 groups ( $p=0.0040$, Fisher-FreemanHalton Test). Given the significant difference found on the FFH test for Grade 3 cases, multiple comparisons for proportions were performed using permutation tests in order to identify the exact source of these differences in frequencies. No significant difference was detected in interpretative results of the multiple comparisons, except for the comparison $0 \%$ versus $0 \%$ ( $p=1.0000$, permutation test).

Table 4 shows a significant difference in frequency of Grade 3 cases between Group 1 and Group 3 ( $0 \%$ versus 62.5\%, permutation test). A similar difference was seen between Group 2 and Group 3.

Table 3 Results of Interpretative analysis of difference in frequency of occurrence of different grades of OM severity among the three groups studied

\begin{tabular}{|c|c|c|c|c|c|}
\hline Variable & $\operatorname{RLG}(n=8)$ & $\operatorname{IRLG}(n=8)$ & $C G(n=8)$ & Total $(n=24)$ & P Value \\
\hline \multicolumn{6}{|l|}{ Grade 0} \\
\hline 0 & $5(62.5 \%)$ & $4(50.0 \%)$ & $8(100.0 \%)$ & I7(70.8\%) & $0.1302^{(*)}$ \\
\hline I & $3(37.5 \%)$ & $4(50.0 \%)$ & $0(0.0 \%)$ & $7(29.2 \%)$ & \\
\hline Total & 8 & 8 & 8 & 24 & \\
\hline \multicolumn{6}{|l|}{ Grade I } \\
\hline 0 & $4(50.0 \%)$ & $5(62.5 \%)$ & $8(100.0 \%)$ & $17(70.8 \%)$ & $0.1302^{(*)}$ \\
\hline I & $4(50.0 \%)$ & $3(37.5 \%)$ & $0(0.0 \%)$ & $7(29.2 \%)$ & \\
\hline Total & 8 & 8 & 8 & 24 & \\
\hline \multicolumn{6}{|l|}{ Grade 2} \\
\hline 0 & $7(87.5 \%)$ & $7(87.5 \%)$ & $6(75.0 \%)$ & $20(83.3 \%)$ & $1.0000^{* \prime \prime}$ \\
\hline I & $\mathrm{I}(\mathrm{I} 2.5 \%)$ & $\mathrm{I}(12.5 \%)$ & $2(25.0 \%)$ & $4(16.7 \%)$ & \\
\hline Total & 8 & 8 & 8 & 24 & \\
\hline \multicolumn{6}{|l|}{ Grade 3} \\
\hline 0 & $8(100.0 \%)$ & $8(100.0 \%)$ & $3(37.5 \%)$ & $19(79.2 \%)$ & $0.0040^{*}$ \\
\hline I & $0(0.0 \%)$ & $0(0.0 \%)$ & $5(62.5 \%)$ & $5(20.8 \%)$ & \\
\hline Total & 8 & 8 & 8 & 24 & \\
\hline \multicolumn{6}{|l|}{ Grade 4} \\
\hline \multicolumn{6}{|c|}{ (Table 3 continue..) } \\
\hline 0 & $8(100.0 \%)$ & $8(100.0 \%)$ & $7(87.5 \%)$ & $23(95.8 \%)$ & $1.0000^{(3)}$ \\
\hline I & $0(0.0 \%)$ & $0(0.0 \%)$ & $\mathrm{I}(\mathrm{I} 2.5 \%)$ & $\mathrm{I}(4.2 \%)$ & \\
\hline Total & 8 & 8 & 8 & 24 & \\
\hline
\end{tabular}

Table 4 Multiple comparisons of frequencies (permutation test)

\begin{tabular}{lll}
\hline p Values & & \\
\hline Variable & Contrast & Permutation test \\
\hline Grade 3 & Group I vs Group 2 & 1.0000 \\
Grade 3 & Group I vs Group 3 & 0.0036 \\
Grade 3 & Group 2 vs Group 3 & 0.0036 \\
\hline
\end{tabular}




\section{Discussion}

The most commonly used antineoplastic agents for cancer treatment includes polyfunctional alkylating agents, antimetabolites, mitotic inhibitors, antibiotics, antitumoral among others. The oral cavity is a frequent target of the toxic effects of these antineoplastic agents. ${ }^{2,9,17}$ The most common manifestation of stomatoxicity is oral mucositis. ${ }^{6}$ This lesion consists of inflammation with consequent ulceration of oral tissues, and represents a potential source of infection that may become life-threatening, particularly in immunosuppressed patients. ${ }^{15}$ The emergence of the condition is linked to the type of antineoplastic treatment proposed and to individual susceptibility. Some authors report a higher incidence of 5-fluoracil-induced oral mucositis among women. ${ }^{22}$ Results of the present study in breast cancer patients showed that use of the FAC combination, comprising the antineoplastic drugs fluorouracil (5-FU), adriamycin (doxorubicin) and cyclophosphamide, triggered cellular and molecular processes that induced oral mucositis. ${ }^{22}$

Laser photobiomodulation appears to be a promising procedure for the management of $\mathrm{OM}$ since it delays the onset, reduces severity and shortens the course of the condition. However, curative applications of laser are apparently less effective than preventive applications. ${ }^{23-25}$ Few studies have related the efficacy of lasers to the physical parameters used in their application. Nevertheless, positive results in pain management and prevention of more severe lesions have been reported, ${ }^{18}$ a finding confirmed by the clinical and statistical results obtained in the present study for the red and infrared laser experimental groups (RLG and IRLG).

In the present assessment of OM severity, no significant difference in frequency of Grade 0 cases was detected among the three groups studied. From a clinical standpoint, however, the use of lasers proved to be effective for the prevention of OM since lesions of lesser severity were observed in the laser irradiated groups versus the control Group.

In the infrared group (IRLG), $50 \%$ of subjects showed no mucosal changes. These results were slightly superior to those obtained for patients from the red laser group (RLG), 50\% of whom had Grade 1 OM. However, no significant differences were observed between the two groups.

In the present study, patients treated with laser showed delayed onset of mucositis and lower degrees of severity compared with patients in the Control Group. Multiple comparisons of frequency using the permutation test revealed significant differences in frequency of Grade 3 cases between Group 1 (RLG) and Group 3 (CG), and likewise between Group 2 (IRLG) and Group 3 (CG) (0\% versus 62.5\%).

In the current sample, low-level laser applied using different physical parameters and employed for preventive purposes, satisfactorily promoted analgesia and biomodulation effects, proving beneficial in patients undergoing adjuvant chemotherapy.

\section{Conclusion}

Based on these results, it can be concluded that the severity of oral mucositis lesions observed in the groups treated with low-level laser was lower than that of the control group, indicating that this treatment modality can be applied to promote improvements in the quality of life of cancer patients. No statistically significant difference in outcomes was found for the two laser wavelengths employed.

\section{Acknowledgements}

None.

\section{Conflict of interest}

The author declares no conflict of interest.

\section{References}

1. Palappallil DS, Nair BL, Jayakumar KL, et al. Comparative study of the toxicity of 5-fluorouracil-adriamycin-cyclophosphamide versus adriamycin-cyclophosphamide followed by paclitaxel in carcinoma breast. Indian J Cancer. 20I I;48(I):68-73.

2. Bensadoun RI, Ciais G. Radiation and chemotherapy-induced mucositis in oncology: results of multicenter phase III studies. J Oral Laser App. 2002;2(2):II5-120.

3. Cheng KKF, Molassiotis A, Chang AM, et al. Evaluation of an oral care protocol intervention in the prevention of chemotherapy-induced oral mucositis in paediatric cancer patients. Eur J Cancer. 2001;37(16):20562063.

4. Dodd MJ, Larson PJ, Dibble SL, et al. Randomized clinical trial of chlorhexidine versus placebo for prevention of oral mucositis in patients receiving chemotherapy. Oncol Nurs Forum. 1996;23(6):921-927.

5. Sonis ST, Elting LS, Keefe D, et al. Perspectives on cancer therapyinduced mucosal injury: pathogenesis, measurement, epidemiology, and consequences for patients. Cancer. 2004; 100(9 Suppl): I995-2025.

6. Migliorati CA, Oberle-Edwards L, Schubert M. The role of alternative and natural agents, cryotherapy, and/or laser for management of alimentary mucositis. Support Care Cancer. 2006; I4(6):533-540.

7. Lima V, Brito GA, Cunha FQ, et al. Effects of the tumour necrosis factoralpha inhibitors pentoxifylline and thalidomide in short-term experimental oral mucositis in hamsters. Eur J Oral Sci. 2005; I 13(3):210-217.

8. Verdi CJ. Cancer therapy and oral mucositis. an appraisal of drug prophylaxis. Drug Saf. 1993;9(3): I85-195.

9. Barasch A, Elad S, Altman A, et al. Antimicrobials, mucosal coating agents, anesthetics, analgesics, and nutritional supplements for alimentary tract mucositis. Support Care Cancer. 2006; I4(6):528-532.

10. Lockhart PB, Sonis ST. Alterations in the oral mucosa caused by chemotherapeutic agents. A histologic study. I Dermatol Surg Oncol. 1981;7(12):1019-1025.

11. Epstein JB, Schubert MM. Oral mucositis in myelosuppressive cancer therapy. Oral Surg Oral Med Oral Pathol Oral RadiolEndod. 1999;88(3):273276.

12. Parulekar W, Mackenzie R, Biarnason G, et al. Scoring oral mucositis. Oral Oncol. I998;34(I):63-7I.

13. Woo SB, Sonis ST, Monopoli MM, et al. A longitudinal study of oral ulcerative mucositis in bone marrow transplant recipients. Cancer. 1993;72(5):1612-1617.

14. Santos PS, Coracin FL, Barros JC, et al. Impact of oral care prior to HSCT on the severity and clinical outcomes of oral mucositis. Clin Transplant. $2011 ; 25(2): 325-328$.

15. Elting LS, Keefe DM, Sonis ST, et al. Patient-reported measurements of oral mucositis in head and neck cancer patients treated with radiotherapy with or without chemotherapy: demonstration of increased frequency, severity, resistance to palliation, and impact on quality of life. Cancer. 2008; II3(I0):2704-27I3. 
16. Campos L, Simões A, Sá PH, et al. Improvement in quality of life of an oncological patient by laser phototherapy. Photomed Laser Surg. 2009;27(2):37I-374.

17. Genot-Klastersky MT, Klastersky J, Awada F, et al. The use of low-energy laser (LEL) for the prevention of chemotherapy-and/or radiotherapyinduced oral mucositis in cancer patients: results from two prospective studies. Support Care Cancer. 2008; I6(I2): | 381-1387.

18. Bensadoun RJ. Low level laser therapy (LLLT): a new paradigm in the management of cancer therapy-induced mucositis? Indian J Med Res. 2006; I 24(4):375-378

19. Antunes HS, de Azevedo AM, da Silva Bouzas LF, et al. Low-power laser in the prevention of induced oral mucositis in bone marrow transplantation patients: a randomized trial. Blood. 2007; 109(5):2250-2255.

20. Wong PC, Dodd MJ, Miaskowski C, et al. Mucositis pain induced by radiation therapy: prevalence, severity, and use of self-care behaviors. J Pain Symptom Manage. 2006;32(I):27-37.
21. KaruT, Pyatibrat L, Kalendo G. Irradiation with $\mathrm{He}-\mathrm{Ne}$ laser increases ATP level in cells cultivated in vitro.J PhotochemPhotobiol B. 1995;27(3):219-223.

22. Chansky K, Benedetti J, Macdonald JS. Differences in toxicity between men and women treated with 5-fluoracil therapy for colorectal carcinoma. Cancer. 2005; 103(6): I|65-II71.

23. Biron P, Sebban C, Gourmet R, et al. Research controversies in management of oral mucositis. Support Care Cancer. 2000;8(I):68-7I.

24. Mester E, Mester AF, Mester A. The biomedical effects of Laser aplications. Lasers Surg Med. 1985;5(I):31-39.

25. Basford JR. Low intensity laser therapy: still not an established clinical tool. Lasers Surg Med. I995; I6(4):331-342. 